\title{
Cross sectional echocardiographic assessment of the extent of the atrial septum relative to the atrioventricular junction in atrioventricular septal defect
}

\author{
S Falcão, L Daliento, S Y Ho, M L Rigby, R H Anderson
}

\begin{abstract}
Objective-To study patients with atrioventricular septal defect to determine the pathognomonic morphological features of the lesion and the relation between the septal structures and the atrioventricular junction.
\end{abstract}

Setting - Tertiary level paediatric cardiology centre.

Methods-Cross sectional echocardiograms from 60 patients were reviewed using qualitative and quantitative analysis. The unifying feature was the presence of a common atrioventricular junction. The overall dimensions of the septal defect were determined and related to the plane of the common junction; the extent of both the atrial and the ventricular septal components was then measured according to the site of closure of the bridging leaflets. Results-In 48 cases, the common junction was guarded by a common valvar orifice, but in 12 cases there were separate right and left valvar orifices. Irrespective of the valvar morphology, no significant difference was found between the groups in terms of the dimensions of the atrial and ventricular septal components. In all patients, the hole permitting shunting at atrial level extended below the plane of the atrioventricular junction, with a variable position of the leading edge of the atrial septum itself.

Paediatrics, Nationa Heart and Lung Institute, Royal Brompton Campus, Imperial College School of Medicine, Dovehouse Street, London SW3 6LY, UK $\mathrm{S}$ Y Ho

M L Rigby

R H Anderson

Paediatric Cardiology, Fundação Hospitalar de Brasilia, Brasil S Falcão

Cattedra di

Cardiologia,

University of Padova,

Italy

L Daliento

Correspondence to: Professor Anderson. email: r.anderson@ic.ac.uk

Accepted for publication 21 September 1998 core of the normal atrioventricular junction. The dominant feature, therefore, is a hole at the centre of the heart, at the expected site of the atrioventricular fibrous septum and the muscular atrioventricular sandwich. ${ }^{3}$ It has also been shown that, despite the septal deficiency, the atrial septum itself is of normal dimensions. ${ }^{4}$ This is important, because some textbooks still describe the "partial" form of the lesion as representing an ostium primum atrial septal defect, ${ }^{5}$ illustrating the lesion in the setting of separate right and left atrioventricular junctions, as in the normal heart, while others similarly argue that the junctional anatomy is not "in common" in this variant of the malformation. ${ }^{6}$ According to our morphological observations, however, it is a common junction that is the pathognomonic feature.${ }^{13} \mathrm{It}$ is, then, the interrelation of the two leaflets of the effectively common valve guarding the junction which bridges the ventricular septum, and their relation to the atrial and ventricular septal structures, that produces the varied anatomical and pathophysiological features within the group. Although there have been echocardiographic and morphological measurements of the atrial and ventricular septal components, ${ }^{4}$ we know of none made in life to determine the extent of these structures relative to the plane of the atrioventricular junction. Our objective was to clarify this point and to confirm the echocardiographic features pathognomonic for the group overall.

\section{Methods}

We analysed cross sectional echocardiograms retrospectively from 60 patients with atrioventricular septal defect seen over the last three years at the directorate of paediatrics of the Royal Brompton Hospital. All echocardiograms were obtained with a Hewlett-Packard 200 phased array machine (Hewlett-Packard Co, Andover, Massachusetts, USA). The patients, 29 of whom were male and 31 female, were aged from 11 days to 39 years (mean 5 years) at the time of the examination.

All showed usual atrial arrangement (solitus), and concordant atrioventricular and ventriculo-arterial connections. No significant obstruction was present in the outflow tracts of either ventricle.

Parasternal long and short axis views and four chamber subcostal long axis and oblique views were used to define the intracardiac anatomy, ${ }^{8-10}$ in particular the insertions of the bridging leaflets. Colour Doppler was used to determine the level of intracardiac shunting (atrial, ventricular, or atrial and ventricular), and to detect any regurgitation across the atrioventricular valves. We described the 

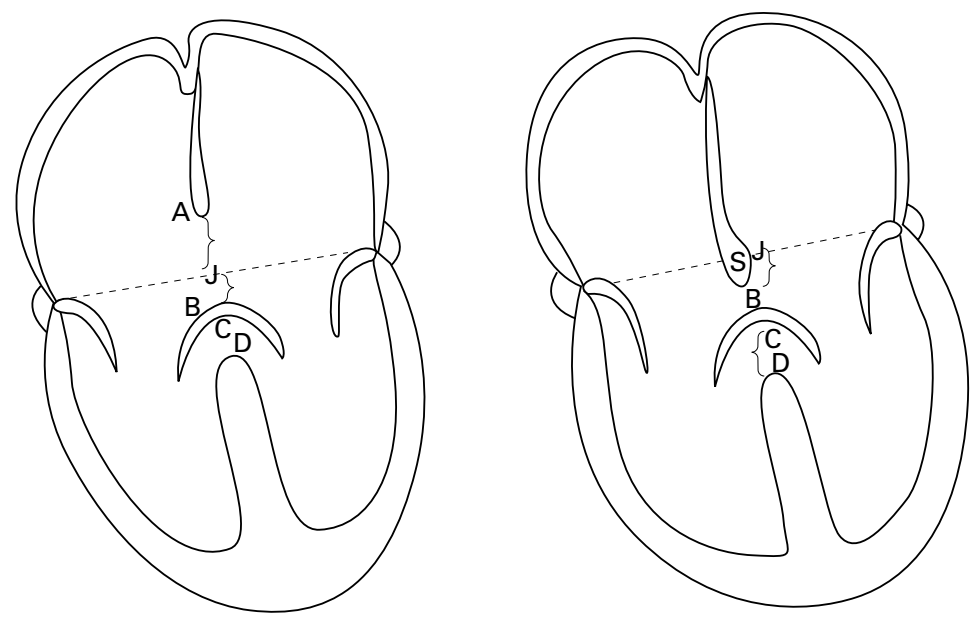

Figure 1 Diagram showing the measurements taken. The plane of the atrioventricular junction is marked by the broken line ( $(\mathcal{)})$, and is taken as the zero point in fig $4 A$ and $4 B$. Note that in the right hand panel the lower edge of the atrial septum is below the level of the atrioventricular junction (S). A, lower edge of the atrial septum; $B$, atrial surface of the bridging leaflet; $C$, ventricular surface of the superior bridging leaflet; $D$, crest of the muscular septum.

number of atrioventricular valvar orifices and the potential for shunting across the atrioventricular septal defect as separate features in
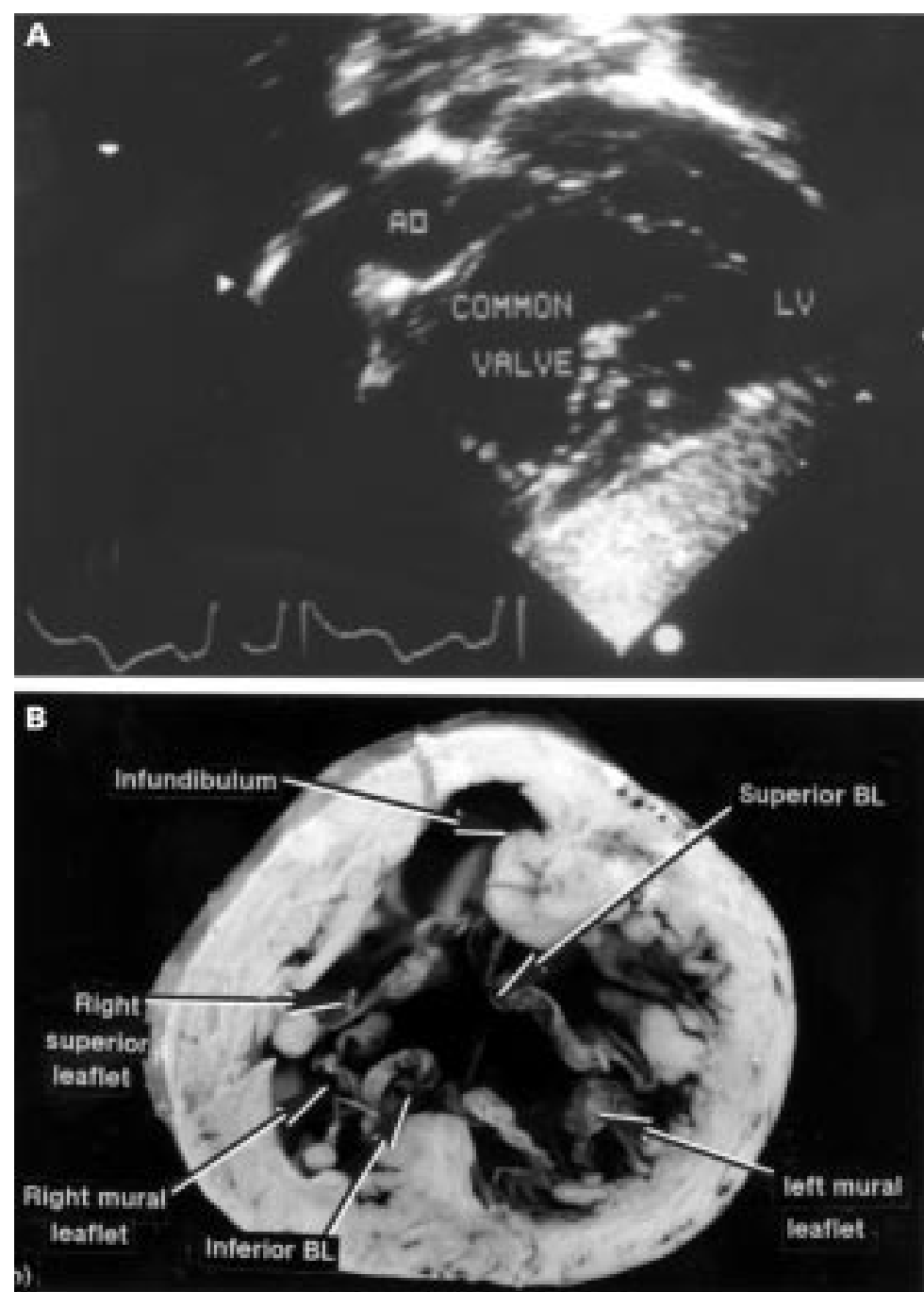

Figure 2 The junctional arrangement of atrioventricular septal defect with common atrioventricular valve shown $(A)$ echocardiographically and $(B)$ in a postmortem specimen from a different patient. AO, aorta; $B L$, bridging leaflet; $L V$, left ventricle. each heart. The insertion of tendinous cords anchoring the bridging leaflets to the septum and the location of the ventricular papillary muscle were noted, these features determining the free floating or tethered nature of the bridging leaflets. The relative size of the ventricles was recorded. When the chambers were of comparable size, the arrangement was considered to be balanced.

Right or left dominance was coded when the commitment of the atrioventricular junction favoured the right or left ventricle, producing reduced dimensions of the complementary ventricle, as seen in apical four chamber sections.

For quantitative analysis, a frame was frozen at the same point of the QRS complex recorded in the simultaneous electrocardiogram. The frame was selected when the atrioventricular valvar leaflets were completely closed and aligned, both atrial and ventricular septa were seen, and the parietal atrioventricular junctions could be identified. We took the origin of the hinge of the valvar leaflets at the parietal fibrofatty atrioventricular grooves as marking the atrioventricular junction. We measured from the lower edge of the atrial septum to the previously marked atrioventricular junction (AJ), and from it to the atrial surface of the superior bridging leaflet (JB). These two variables together gave the size of the defect through which shunting can occur at atrial level (AB). We also measured from the underside of the superior bridging leaflet to the crest of muscular ventricular septum (CD), this dimension determining the extent of ventricular shunting when present. We then assessed the location of the entirety of the atrioventricular septal defect relative to the plane of the atrioventricular junction, taking this plane as zero point (fig 1). All patients were in sinus rhythm. Extrasystolic and postextrasystolic cycles were excluded.

\section{Results}

All patients had a common atrioventricular junction, defined as the area around which the atrial myocardium inserted into the crest of the ventricular muscle mass. This feature distinguishes the group from all normal hearts, which possess separate right and left atrioventricular junctions, and the majority of congenitally malformed hearts, which also possess discrete right and left atrioventricular junctions. The common atrioventricular junction, however, was guarded by a common valvar orifice in only 48 patients (fig $2 \mathrm{~A}$ and $2 \mathrm{~B}$ ). In the other 12 patients, there were separate valvar orifices guarding the entrances to the right and left ventricles, but within a common atrioventricular junction (fig 3). In those with common valves, two of the leaflets bridged the crest of the ventricular septum, with the potential for interventricular shunting beneath the bridging leaflets. The bridging leaflets had cordal insertions to the crest of the muscular ventricular septum in 34 cases. The superior bridging leaflet was tethered towards the apical aspect of ventricular septum, without any direct septal attachments, in eight cases. It was free floating in six further patients, being tethered to a 
parietal apical papillary muscle in the right ventricle. Quantitative and qualitative data of
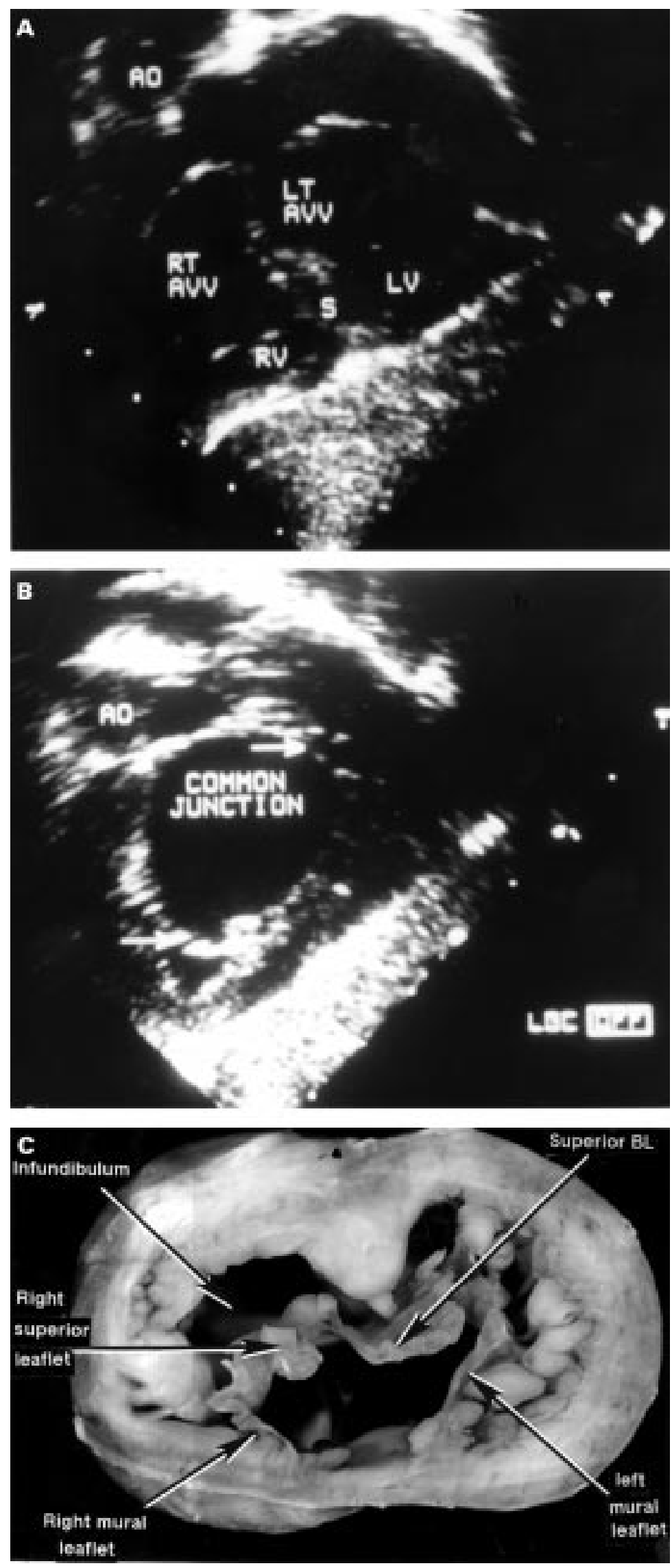

the groups of patients with common valvar orifice, as opposed to separate right and left valvar orifices within the common junction, are summarised in tables 1 and 2, respectively.

The location of shunting through the atrioventricular septal defect reflected the relation between the bridging leaflets and the atrial and ventricular septal structures. In all 12 cases with separate right and left valvar orifices, shunting occurred exclusively at atrial level. Shunting was predominantly at atrial level in 23 cases with common valvar orifice and both bridging leaflets tethered to the crest of the ventricular septum. In 21 patients with a common orifice, the potential for shunting was predominantly at ventricular level. In the other four patients, the potential for shunting was equal at atrial and ventricular levels. The ventricles were balanced in 38 cases, and there was right ventricular dominance in eight and left ventricular dominance in two.

It proved possible in all the cases to determine the extent of the atrial and ventricular components of the atrioventricular septal defect. In patients with common valvar orifice, the mean (SD) values for the atrial and ventricular components were $0.74(0.59)$ and $0.72(0.40) \mathrm{cm}$, respectively. The mean value for the size of the entire atrioventricular septal defect was $1.63(0.89) \mathrm{cm}$. In patients with a common atrioventricular junction but two separate valvar orifices for the right and left ventricles, the mean size of the defect, which permitted shunting only at atrial level, was 0.81 $(0.61) \mathrm{cm}$.

In cases with a common valvar orifice (fig $4 \mathrm{~A}$ ), the mean distance from the lower edge of the atrial septum to the site of the atrioventricular junction (AJ) was $0.38(0.45) \mathrm{cm}$, and from the junction to the atrial surface of the superior bridging leaflet (JB) it was $0.42(0.29)$ $\mathrm{cm}$. In patients with separate atrioventricular valvar orifices for the two ventricles, the dimensions of the septal defect above and below the atrioventricular junction were 0.52 $(0.51)$ and $0.55(0.40) \mathrm{cm}$, respectively (fig $4 \mathrm{~B})$. There was no significant difference in these dimensions between patients with a common valve and those with separate valvar orifices.

In the group with common atrioventricular valve, there were 12 patients (25\%) with shunting at atrial level, but exclusively below the plane of the atrioventricular junction, because the atrial septum extended to the plane of the atrioventricular junction. Indeed, in five of these, the atrial septum was below the level of the atrioventricular junction, extending for $0.30(0.24) \mathrm{cm}$ into the ventricular cavity at the

Figure 3 Comparable echocardiographic cuts $(A, B)$ and a cross section from the heart of a different patient $(C)$ showing the junctional arrangement in atrioventricular septal defect with common atrioventricular junction, but with separate valvar orifices for the right and left ventricles. The more distal echo cut $(A)$ shows the common junction relative to the ventricular septum(s). As shown by the more proximal cut (B), at the level of the defect itself, the septum is not seen and the junction is obviously common (between arrows). This is confirmed by the cut of the postmortem specimen. $A O$, aorta; $B L$, bridging leaflet; $L V$, left ventricle; $R T A V V, L I A V V$, right and left atrioventricular valves; $R V$ right ventricle. 
Table 1 Quantitative and qualitative analysis of the atrioventricular septal defect with common valvar orifices

\begin{tabular}{|c|c|c|c|c|c|c|c|c|}
\hline Patient & $A B$ & $C D$ & $A V S D$ & $S$ & $A \mathcal{F}$ & $\mathscr{f} B$ & Type & Ventricle \\
\hline 1 & 0.27 & -1.40 & 0.50 & & 0.10 & -0.05 & A & BAL \\
\hline 2 & 0.50 & -0.50 & 1.10 & & 0.10 & -0.40 & A & BAL \\
\hline 3 & 0.20 & -0.50 & 0.80 & & 0.00 & -0.20 & A & BAL \\
\hline 4 & 0.60 & -0.17 & 0.54 & -0.10 & & -0.57 & A & BAL \\
\hline 5 & 0.30 & -1.00 & 1.50 & & 0.10 & -0.20 & A & BAL \\
\hline 6 & 0.40 & -0.30 & 1.10 & & 0.10 & -0.37 & C & RVD \\
\hline 7 & 1.00 & -0.10 & 1.47 & & 0.70 & -0.35 & A & BAL \\
\hline 8 & 1.44 & -0.72 & 2.20 & & 0.56 & -0.88 & A & BAL \\
\hline 9 & 1.35 & -1.10 & 2.37 & & 1.05 & -0.30 & B & BAL \\
\hline 10 & 0.20 & -0.80 & 1.50 & -0.30 & & -0.56 & A & BAL \\
\hline 11 & 0.37 & -0.50 & 1.00 & & 0.27 & -0.10 & A & BAL \\
\hline 12 & 1.50 & -1.50 & 3.16 & & 0.46 & -1.06 & $\mathrm{C}$ & RVD \\
\hline 13 & 0.40 & -0.45 & 0.90 & & 0.15 & -0.25 & B & BAL \\
\hline 14 & 0.75 & -0.35 & 1.20 & -0.30 & & -1.05 & A & BAL \\
\hline 15 & 0.25 & -0.60 & 1.25 & & 0.00 & -0.25 & A & BAL \\
\hline 16 & 0.40 & -0.60 & 1.20 & & 0.00 & -0.40 & B & LVD \\
\hline 17 & 0.35 & -0.30 & 1.00 & & 0.10 & -0.25 & A & BAL \\
\hline 18 & 0.40 & -1.10 & 1.60 & & 0.10 & -0.30 & $\mathrm{~A}$ & $\mathrm{BAL}$ \\
\hline 19 & 1.45 & -1.10 & 2.60 & & 1.35 & -0.10 & A & BAL \\
\hline 20 & 0.80 & -0.60 & 1.60 & & 0.10 & -0.75 & A & BAL \\
\hline 21 & 0.70 & -0.50 & 1.25 & & 0.35 & -0.35 & A & BAL \\
\hline 22 & 3.10 & -1.00 & 4.60 & & 2.20 & -0.90 & A & BAL \\
\hline 23 & 2.70 & -0.60 & 1.25 & & 0.25 & -0.20 & A & BAL \\
\hline 24 & 1.30 & -0.85 & 2.10 & & 0.50 & -0.60 & A & BAL \\
\hline 25 & 0.15 & -0.37 & 1.17 & & 0.00 & -0.15 & A & BAL \\
\hline 26 & 1.00 & -0.80 & 2.20 & & 0.75 & -0.27 & C & BAL \\
\hline 27 & 1.00 & -0.70 & 2.20 & & 0.60 & -0.40 & A & BAL \\
\hline 28 & 0.17 & -0.80 & 1.30 & & 0.00 & -0.17 & A & BAL \\
\hline 29 & 0.80 & -0.60 & 1.80 & & 0.50 & -0.37 & A & BAL \\
\hline 30 & 0.10 & -0.25 & 0.80 & -0.10 & & -0.25 & A & BAL \\
\hline 31 & 1.20 & -2.00 & 4.00 & & 0.30 & -0.90 & A & $\mathrm{BAL}$ \\
\hline 32 & 1.50 & -1.50 & 3.30 & & 0.56 & -1.00 & A & BAL \\
\hline 33 & 0.17 & -0.50 & 1.12 & & 0.12 & -0.37 & B & BAL \\
\hline 34 & 2.40 & -0.75 & 3.50 & & 1.60 & -0.80 & A & BAL \\
\hline 35 & 0.70 & -0.60 & 1.70 & & 0.50 & -0.27 & B & BAL \\
\hline 36 & 0.80 & -0.25 & 1.70 & & 0.37 & -0.48 & A & BAL \\
\hline 37 & 0.47 & -1.07 & 1.80 & & 0.10 & -0.37 & B & BAL \\
\hline 38 & 0.54 & -0.35 & 1.00 & & 0.37 & -0.17 & A & BAL \\
\hline 39 & 0.50 & -0.80 & 1.50 & & 0.30 & -0.20 & B & LVD \\
\hline 40 & 0.30 & -0.80 & 1.50 & & 0.15 & -0.20 & A & BAL \\
\hline 41 & 0.20 & -0.17 & 0.50 & & 0.17 & -0.05 & B & RVD \\
\hline 42 & 0.80 & -0.80 & 1.60 & & 0.35 & -0.45 & C & RVD \\
\hline 43 & 0.50 & -0.80 & 1.00 & -0.70 & & -1.20 & A & BAL \\
\hline 44 & 0.30 & -0.40 & 0.90 & & 0.00 & -0.30 & C & RVD \\
\hline 45 & 0.20 & -0.35 & 0.60 & & 0.00 & -0.20 & A & RVD \\
\hline 46 & 0.50 & -0.90 & 1.40 & & 0.25 & -0.25 & C & RVD \\
\hline 47 & 1.10 & -0.48 & 2.05 & & 0.50 & -0.60 & A & BAL \\
\hline 48 & 0.90 & -0.70 & 1.60 & & 0.50 & -0.40 & A & BAL \\
\hline
\end{tabular}

Values in $\mathrm{cm}$.

$\mathrm{AB}$, size of the atrial component; AJ, dimension from the level of the atrioventricular junction to lower edge of the atrial septum; AVSD, size of the atrioventricular defect; BAL, balanced ventricle; CD, size of the ventricular component; JB, dimension from the plane of the atrioventricular junction to atrial surface of the superior bridging leaflet; LVD, left ventricular dominance; RVD, right ventricular dominance; S, septum; Type, according to Rastelly classification (A, B, C).

Table 2 Quantitative analysis of atrioventricular septal defect with two separate valvar orifices

\begin{tabular}{lllll}
\hline Patient & $A B$ & $S$ & $A \mathcal{F}$ & $\mathcal{F B}$ \\
\hline 1 & 0.80 & & 0.48 & -0.40 \\
2 & 0.65 & & 0.37 & -0.27 \\
3 & 0.60 & & 0.37 & -0.30 \\
4 & 0.70 & & 0.30 & -0.40 \\
5 & 0.60 & & 0.00 & -0.60 \\
6 & 1.90 & & 1.20 & -0.70 \\
7 & 0.05 & -0.10 & & -1.70 \\
8 & 0.75 & & 0.10 & -0.60 \\
9 & 1.72 & & 1.50 & -0.20 \\
10 & 0.20 & & 0.00 & -0.20 \\
11 & 0.20 & -0.26 & & -0.50 \\
12 & 1.60 & & 0.90 & -0.70 \\
\hline
\end{tabular}

Values in $\mathrm{cm}$.

$\mathrm{AB}$, size of the atrial component; $\mathrm{AJ}$, dimension from the lower edge of the atrial septum to the level of the atrioventricular junction; JB, dimension from the atrioventricular junction to the atrial surface of the superior bridging leaflet; S, septum.

time selected for measurement (fig 5A). These features were also observed in four patients (33\%) with separate valvar orifices for the right and left ventricles. In two of these, the septum reached down to the level of the atrioventricular junction while in the other two the lower margin of the septum was below the atrioventricular junction, extending into the ventricular mass for a distance of $0.18(0.24) \mathrm{cm}$ (fig 5B). The differences between the two groups were again non-significant.

In all cases with common valve in which the leading edge of the atrial septum extended below the plane of the atrioventricular junction, tendinous cords attached the superior bridging leaflet to the crest of the muscular ventricular septum (Rastelli type A). All had balanced ventricles. In seven cases with common valve in which the atrial septum reached to the level of the atrioventricular junction, five had attachments to the ventricular septum with balanced ventricles, but in two cases the leaflet was tethered by a papillary muscle displaced down the right ventricular aspect of the septum (Rastelli type B), albeit still with balanced ventricles.

\section{Discussion}

The atrioventricular junctions are the muscular areas which surround the orifices of the atrioventricular valves. Two such junctions are found in the normal heart, surrounding the orifices of the mitral and tricuspid valves. In such normal hearts, the potential exists for the 
presence of an atrioventricular septum because of the location of the valvar orifices within the bases of the ventricular mass. This potentially septal area is composed of two parts. One is the fibrous atrioventricular septum; the other is the atrioventricular muscular septum, strictly a sandwich because a wedge of extracardiac fibroadipose tissue interposes between the atrial and ventricular musculatures throughout the area. Irrespective of such niceties, this muscular area-between the offset hinges of the mitral and tricuspid valvar leaflets and the fibrous atrioventricular septum - is totally lacking in so called atrioventricular septal, or canal, defects. Despite the septal deficiency, however, the pathognomonic feature of the overall group of hearts is the presence of a common atrioventricular junction. ${ }^{13}$ Within this common junction, there may be a common atrioventricular valvar orifice (so called "complete" defects), or separate right and left valvar orifices for the right and left ventricles (so called "partial" defects-or ostium primum atrial septal defect). In this partial variant, however, the attachment of the bridging leaflets to the ventricular septum, which confines shunting at atrial level, is no longer related to the atrioventricular junction. This is because of the deep "scoop" found in the ventricular septum, with the conjoined valvar leaflets of the right and left orifices attached along the length of the scoop. When analysing the so called

A

$\begin{array}{lll}0.37 & -0.48 & -0.25\end{array}$

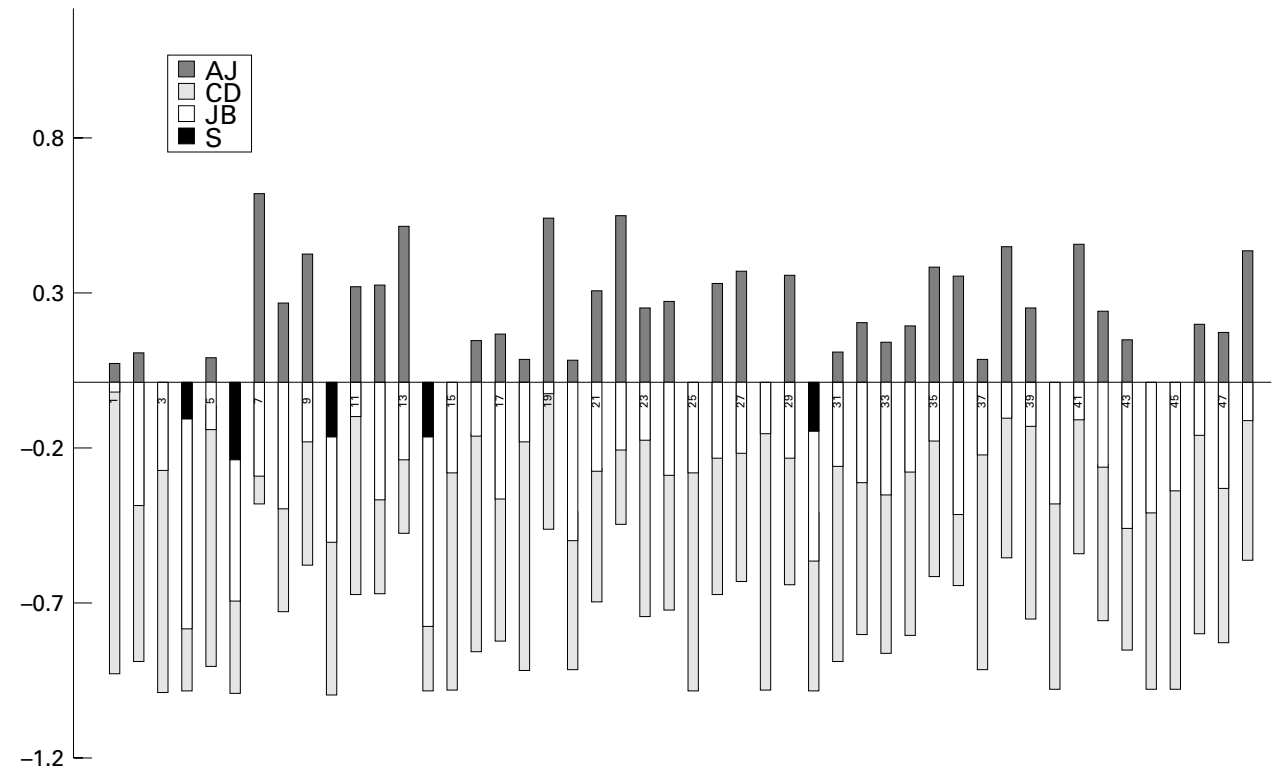

B

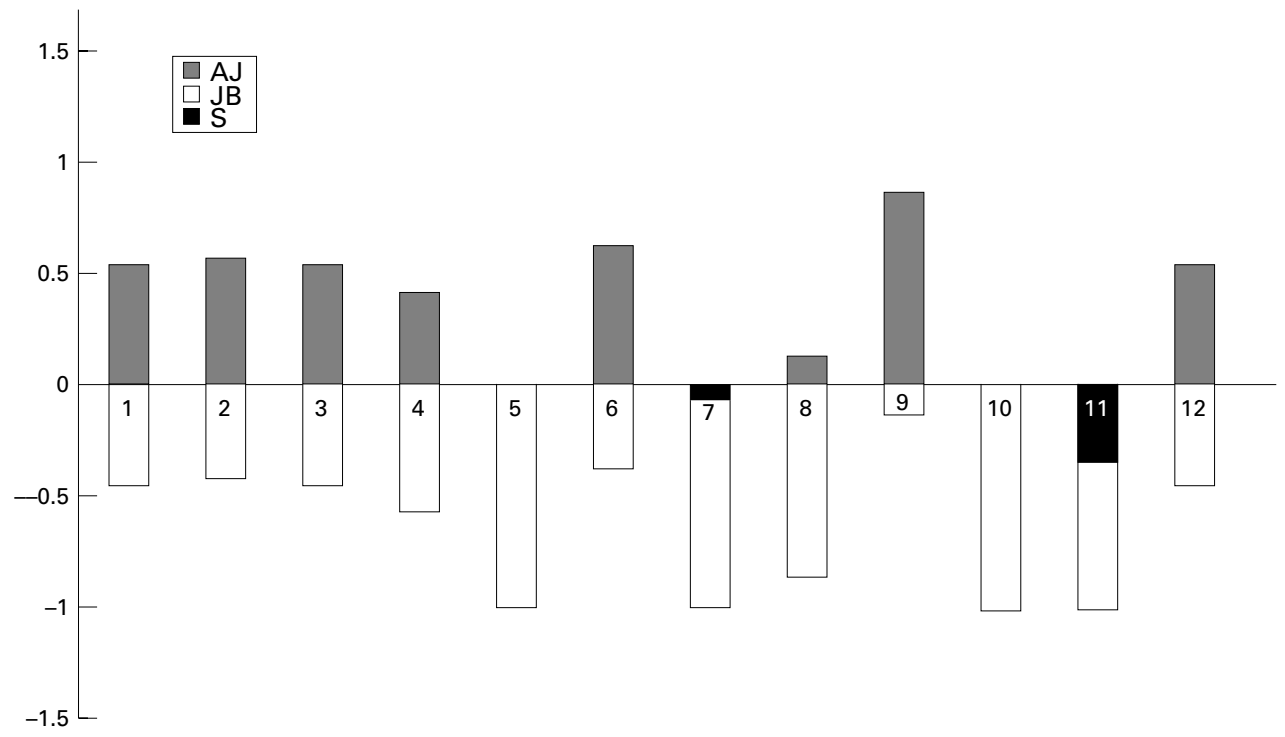

Figure 4 (A) Quantitative analysis from a series of patients with atrioventricular septal defect with common

atrioventricular valvar orifices. The point zero corresponds to the level of atrioventricular junction. (B) Similar quantitative analysis from the series of patients with atrioventricular septal defect and separate atrioventricular orifices for right and left ventricles. Af, dimension of the atrial component above the level of the junction; $C D$, ventricular component; $\mathcal{F B}$, dimension of the atrial component below the plane of the junction; $S$, septum. 

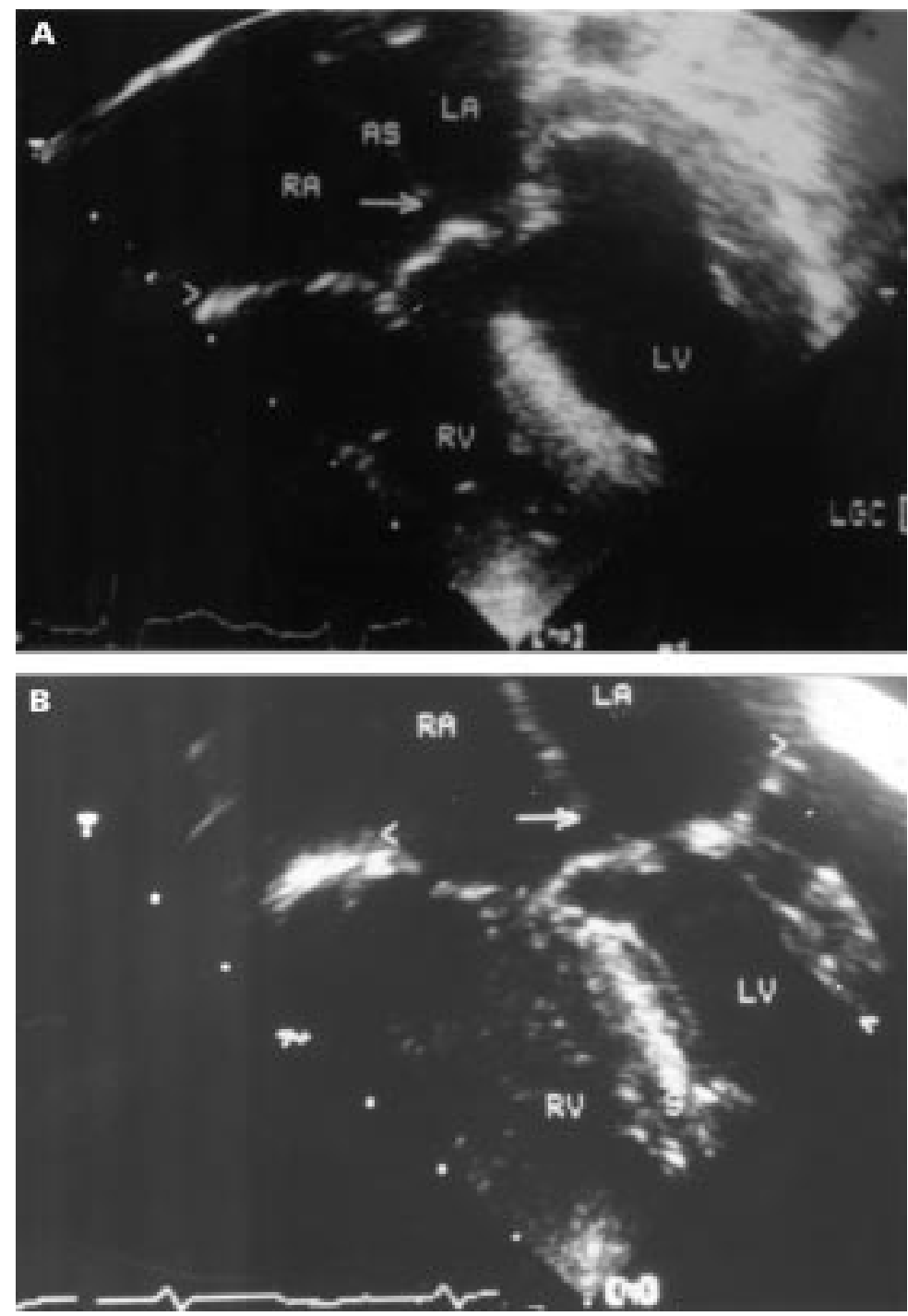

Figure 5 Apical four chamber view (A) from a patient with common atrioventricular junction and common valvar orifice. The plane of the atrioventricular junction is marked $(<>)$. The lower edge of the atrial septum is below the level of the junction (arrow). (B) Similar cut from a patient with common atrioventricular junction, but separate right and left atrioventricular valvar orifices. As in (A), the atrial septum extends below (arrow) the level of the atrioventricular junction. AS, atrial septum; $L A$, left atrium; LV, left ventricle; $R A$, right atrium; $R V$, right ventricle; $S$, ventricular septum.

"ostium primum" defect, therefore, it is important to distinguish between the attachments of the valvar leaflets and the arrangement of the junctional myocardium. The valvar leaflets guard separate right and left atrioventricular orifices, but within the setting of a common atrioventricular junction. It is this common junction which is the key to echocardiographic recognition.

It is also the case that, traditionally, the atrial septum was considered to be poorly developed, its presumed deficiency being considered responsible for the shunting at atrial level. In an elegant echocardiographic study, Gutgesell and Huhta $^{4}$ showed that the atrial septum was of normal dimensions. Our study confirms these findings. Furthermore, we have found that, using the echocardiographic images established by others as diagnostic for the entity, ${ }^{8-10}$ it is possible to identify precisely the location of the atrioventricular junctions, and to determine the levels of the atrial and ventricular septal components relative to the junction. In all our patients, irrespective of the presence of a common atrioventricular orifice or separate and left atrioventricular orifices, part of the septal deficiency was below the level of the atrioventricular junction, despite permitting shunting at atrial level. This feature was most obvious in those with separate right and left valves, in which the displaced bridging leaflets were firmly tethered to the crest of the ventricular septum. Furthermore, in one quarter of these cases, we were surprised to find that, at the point of the cardiac cycle at which we made our measurements, part of the muscular atrial septum extended to, or below, the plane of the atrioventricular junction. Thus, despite the presence of unequivocal shunting at atrial level, there was nothing wrong with the extent of the atrial septum.

The presence of the common atrioventricular junction is also pertinent to consideration of those cases that have intact septal structures, and their distinction from the so called isolated cleft of the mitral valve. ${ }^{11} 12$ In those with a common atrioventricular junction, even if the septal structures are intact, ${ }^{13}{ }^{14}$ there is a trifoliate left atrioventricular valve and a narrowed left ventricular outflow tract. In those with the "isolated" cleft, there are separate right and left atrioventricular junctions, with the subaortic outflow tract normally located within the left ventricle. It is knowledge of the relation between the septal structures and the common atrioventricular junction that underscores the appropriate interpretation of the lesions. The common atrioventricular junction can be guarded by a common atrioventricular valve or two valvar orifices without disturbing the basic structure of the ventricular mass. On the basis of the observed morphology, there is no justification for nominating these two groups as "complete" and "partial" variants. It is, nonetheless, important to distinguish them clinically because, self evidently, they have markedly different haemodynamic characteristics.

We are indebted to Professor A N Redington and Dr E A Shinebourne, in whose care were many of the patients included in this study. We also thank Mr Manjit Josen for his considerable help in the recording of the echocardiographic images and Ms Karen McCarthy for producing the photographic reproducKaren McCarthy for producing the photographic reproduc-
tions. The study would not have been possible without the suptions. The study would not have been possible without the sup-
port grant made by the British Heart Foundation to Professor port grant made by the British Heart Foundation to Professor
Anderson and Dr Ho. Professor Anderson is also supported by Anderson and Dr Ho. Profes
the Joseph Levy Foundation. what's in a name? 7 Thorac Cardiovasc Surg 1982;83:461-9.

2 Van Praagh R, Papagiannis J, Bar-El YI, et al. The heart in Down syndrome - pathologic anatomy. In: Marino B, Pueschel SM, eds. Heart disease in persons with Down syndrome. schel SM, eds. Heart disease in persons with Down syndrome.

3 Anderson RH, Ho SY, Falcão S, et al. The diagnostic features of atrioventricular septal defect with common atrioventricular junction. Cardiology in the Young 1998;8: 33-49.

4 Gutgesell HP, Huhta JC. Cardiac septation in atrioventricular canal defect. $\mathcal{F}$ Am Coll Cardiol 1986;8:1447-50.

5 Feldt RH, Porter CJ, Edwards WD, et al. Atrioventricular septal defects. In: Emmanouilides GC, Allen HD, Riemenschneider TA, et al, eds. Moss and Adams heart disease in infants, children, and adolescents. Baltimore: Williams and Wilkins, 1995:706-7.

6 Castaneda AR, Jonas RA, Mayer JE, et al. Cardiac surgery of neonates and infants. Philadelphia: WB Saunders Co, 1994: 167-86.

7 Penkoske PA, Neches WH, Anderson RH, et al. Further observations on the morphology of atrioventricular septal defects. F Thorac Cardiovasc Surg 1985;90:611-22. 
8 Smallhorn JF, Tommasini C, Anderson RH, et al. Assessment of atrioventricular septal defect by two dimensional ment of atrioventricular septal defect by two

9 Cohen MS, Jacobs ML, Weinberg PM, et al. Morphometric analysis of unbalanced common atrioventricular canal using two-dimensional echocardiography. $\mathcal{F} \mathrm{Am}$ Coll Cardiol 1996;28:1017-23.

10 Cabrera A, Pastor E, Galdeano JM, et al. Cross sectional echocardiography in the diagnosis of atrioventricular septal defect. Int $\mathcal{f}$ Cardiol 1990;28:19-23.

11 Smallhorn JF, de Leval M, Stark J, et al. Isolated anterior mitral cleft. Two dimensional echocardiographic assess- ment and differentiation from "clefts" associated with atrioventricular septal defect. Br Heart f 1982;48:109-16. 12 Sigfússon G, Ettedgui JA, Silverman NH, et al. Is a cleft in the anterior leaflet of an otherwise normal mitral valve an atrioventricular canal malformation? $\mathcal{f} \mathrm{Am}$ Coll Cardiol 1995;26:508-15.

13 Ho SY, Russell G, Gerlis LM. Atrioventricular septal defect with intact septal structures in a 74 -year-old. Int $\mathcal{F}$ Cardiol 1990;26:371-3.

4 Silverman NH, Ho SY, Anderson RH, et al. Atrioventricular septal defect with intact atrial and ventricular septal structures. Int f Cardiol 1984; 5:567-72.

\section{IMAGES IN CARDIOLOGY}

\section{Left ventricular wall thickening after surgical correction of anomalous origin of left coronary artery from pulmonary artery}

A 37 year old hypertensive woman was hospitalised for evaluation of a heart murmur. Echocardiography showed left ventricular hypertrophy with ventricular septum thickness (VST) of $15 \mathrm{~mm}$ and left ventricular posterior wall thickness (LVPWT) of $12 \mathrm{~mm}$. Left ventricular mass index (LVMI) and relative wall thickness (RWT) were $229 \mathrm{~g} / \mathrm{m}^{2}$ and 0.68 , respectively. Magnetic resonance imaging also revealed mild left ventricular hypertrophy (left). Coronary angiography showed anomalous origin of the left coronary artery from the pulmonary artery and severe dilatation of both right and left coronary arteries. Pulmonary-systemic flow ratio was 2.0. Surgical correction was performed by direct reimplantation. One week after surgery, the patient had exertional dyspnoea. Echocardio- graphy and magnetic resonance imaging (right) showed increased left ventricular thickness (VST, $20 \mathrm{~mm}$; LVPWT, $19 \mathrm{~mm}$ ). RWT was profoundly increased to 1.30 and LVMI was unchanged $\left(226 \mathrm{~g} / \mathrm{m}^{2}\right)$. Six months later, left ventricular wall thickness regressed to the preoperative size (VST, $16 \mathrm{~mm}$; LVPWT, $12 \mathrm{~mm}$ ), and symptoms had disappeared.

The left ventricular mass was unaltered, although the left ventricular cavity size was substantially reduced and severe left ventricular wall thickening appeared transiently after closure of the left to right shunt, presumably owing to the rapid reduction of left ventricular volume. The increase in left ventricular wall thickness caused uncompensated diastolic dysfunction and exertional dyspnoea.
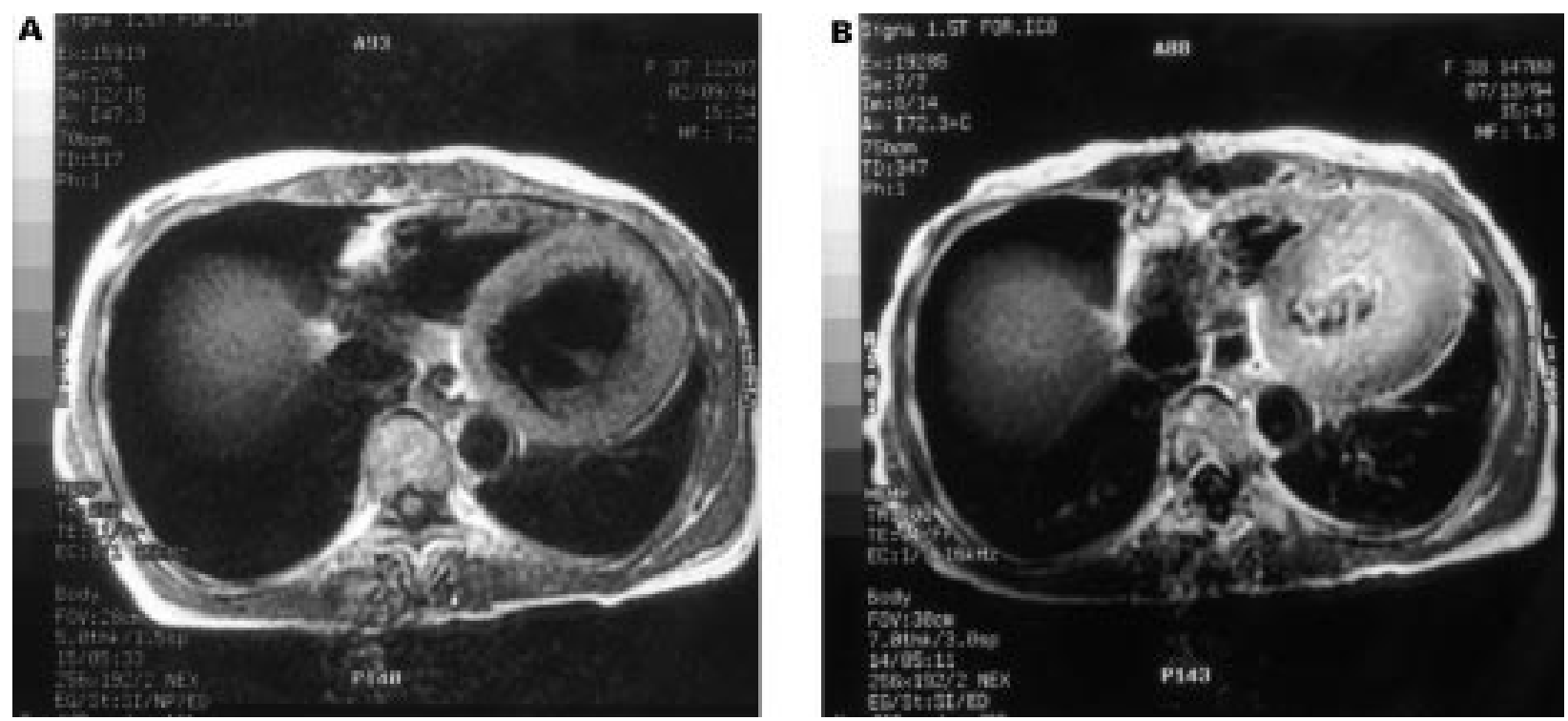

UICHI IKEDA YOSHIAKI MURAKAMI KAZUYUKI SHIMADA 